\title{
Placentophagia in Nonpregnant Rats: Influence of Estrous Cycle Stage and Birthplace'
}

\author{
MARK B. KRISTAL ${ }^{2}$ AND GARY C. GRABER \\ Department of Psychology, State University of New York at Buffalo, Buffalo, NY 14226
}

(Received 12 January 1976)

\begin{abstract}
KRISTAL, M. B. AND G. C. GRABER. Placentophagia in nonpregnant rats: influence of estrous cycle stage and birthplace. PHYSIOL. BEHAV. 17(4) 599-605, 1976. - Prior parturitional experience and genoty pe have previously been found to affect the proportion of nonpregnant female rats and mice that will eat foster placenta. The present series of experiments was designed to investigate the influence of estrous cycle stage on placentophagia in rats. Foster placenta was presented to nonpregnant Long-Evans females, purchased from a commercial breeder, for $15 \mathrm{~min}$ on 5 consecutive days. We found that virgin placentophages were most likely to have eaten placenta on the first presentation, unless the first presentation occurred during proestrus. In fact, virgins would not eat placenta for the first time during proestrus, regardless of test-day. However, once they had eaten placenta, either in a nonproestrus stage, or, in the case of primiparae, during parturition, they would eat placenta during proestrus. Long-Evans rats born in our laboratory differed from the purchased rats, manifesting an incidence of placentophagia that was too low to be analyzed by stage of the estrous cycle; when tested as primiparae, however, there were no differences between the two groups.
\end{abstract}

Placentophagia Estrous cycle Birthplace Parturitional experience Maternal behavior

A CHARACTERISTIC component of perinatal maternal behavior in most infrahuman placental mammalian species is placentophagia - the consuming of all, or part, of the afterbirth $[8,11]$. Numerous hypotheses have arisen regarding the causes and the immediate and long-term consequences of this behavior $[8,11,15]$. Only work pertaining to the proximal determinants of placentophagia will be considered here.

The most frequently discussed hypotheses of the causes of placentophagia are those of general hunger, produced by anorexia associated with the discomfort of labor, and of specific hungers brought about by physiological changes during late pregnancy and parturition. The specific hungers, or specific needs, postulated, consist of either specific nutritional requirements [9] or a specific need for hormones contained in the placenta [15], such as placental lactogen, progesterone, and estrogen. The specific-hunger hypothesis relating to nutritional needs has given rise to the notion of a need, or at least a preference, for meat, which has led researchers to describe parturient females, particularly of omnivorous and herbivorous species, as temporarily carnivorous $[2,3,8]$.

Certain of these hypotheses have not stood up under empirical examination. In regard to the general-hunger hypothesis, the rat, a most reliable placentophage which does not have a protracted labor period, does not exhibit decreased food intake during the last $24 \mathrm{hr}$ of pregnancy [6]. In regard to the hypothesis of a shift to carnivorousness, (i.e., a sudden preference for meat, per se) at parturition, studies both on rats [4] and on rhesus macaques [13] indicate that the preference during the perinatal period is specifically for placenta, since other meat substances are refused.

Implicit in the hypothesis that physiological changes in late pregnancy produce a specific need for substances contained in placenta, is the assumption that placentophagia is unique to the parturitional situation. Of course, that is when placentophagia is ordinarily observed because that is usually the only time placenta is available to the female. However, Kristal $[4,5,7]$ has demonstrated that if foster placenta is made available to groups of nonpregnant rats or mice, some proportions of the groups do manifest placentophagia.

Placentophagia in nonpregnant female rodents has been shown to be strongly influenced by strain [7], ultimately reducible to the action of two nonallelic genes [5], and influenced, even more strongly, by prior experience $[4,7]$. Not only does the proportion of nonpregnant placentophagic females increase as a result of prior parturitional experience, but prior parturitional experience, and not the parturient condition at the time of testing, has been found to be the predictor of placentophagia in female rats made

\footnotetext{
${ }^{1}$ Research supported in part by National Institute of Mental Health Grant MH-25747, and in part by Institutional Funds from the State University of New York at Buffalo, both awarded to Mark B. Kristal.

${ }^{2}$ Reprint requests should be addressed to: Mark B. Kristal, Department of Psychology, SUNYAB, 4230 Ridge Lea Road, Buffalo, N. Y. 14226.
} 
aphagic and adipsic by lateral hypothalamic lesions [4].

That placentophagia is exhibited by nonpregnant females does not conflict with the notion that placentophagia in the parturient female is initiated by hormonal needs or hormonal changes. Furthermore, it is possible that if hormonal changes at parturition influence placentophagia, then hormonal changes associated with the estrous cycle might affect placentophagia in the nonpregnant female. Information on possible estrous-cycle determinants of placentophagia is critical to our understanding of the factors affecting the animal's base-level response to placenta - that response manifested by virgin females.

The research to be reported here is presented as a series of experiments for purposes of exposition. It should be noted, however, that certain groups (e.g., CR-born Nulliparous, in Experiment 1) serve as the basis for comparison in more than one experiment.

\section{EXPERIMENT 1}

Experiment 1 was designed to determine what proportion of Long-Evans (hooded) virgin females would manifest placentophagia when presented with foster placenta, and whether the stage of the estrous cycle during testing affected the likelihood of the response. Preliminary observations in our laboratory indicated that the location of birth and rearing of the females (the Charles River Breeding Laboratories vs our laboratory) also affected the likelihood of placentophagia in virgins; therefore, females from both locations were tested.

\section{METHOD}

\section{Animals}

Virgin female rats of the Long-Evans (hooded) strain, $90-150$ days of age, weighing $225-280 \mathrm{~g}$, were tested. The females were either purchased at 60-70 days of age from the Charles River Breeding Laboratories (CR-born; $n=127)$ or were born and raised in our laboratory (on Ridge Lea Road) and were the daughters of CR-born rats (RL-born; $n$ $=74)$. Females that served as placenta donors were CR-born, Long-Evans females that had not given birth previously.

All females were housed in pairs in $18 \times 18 \times 24 \mathrm{~cm}$ wire-mesh cages and maintained on a 6:00 a.m.- 8:00 p.m. (EST) daylight cycle. Dry food (Charles River Rat/Mouse/Hamster Formula) and water were available ad lib.

\section{Procedure}

Placenta collection. Placentas for test presentation were obtained surgically on the last full day of pregnancy (Day 21) from $\mathrm{CO}_{2}$-killed, time-bred donors. The placentas were placed in $6 \mathrm{ml}$ screw-cap vials ( 3 placentas/vial) along with 5 drops of physiological saline. The vials were then placed in a freezer at $-20^{\circ} \mathrm{C}$ until needed for testing.

Placenta presentation. On the days of testing, the vials were removed from the freezer and placed in warm water until the placentas reached about $30^{\circ} \mathrm{C}$. The placentas were then removed from the vial and placed in $37 \mathrm{~mm}$ (dia.) glass Stender dishes ( 1 or 2 placentas/dish) which were then immediately presented to $2 \mathrm{hr}$ food-deprived, $15 \mathrm{~min}$ water-deprived females, in their home cages. Each female was allowed $15 \mathrm{~min}$ of exposure to the dish of placenta.
Testing took place between 1:00 and 3:00 p.m. Only the presence or absence of placentophagia was noted, since here, as in previous studies, placentophagic females consumed all of the placenta presented, and nonplacentophagic females consumed none. Each female was tested for 5 consecutive days, or until she manifested placentophagia.

Vaginal smears. Vaginal smears were obtained immediately after testing from each test female on the day on which she ate placenta, if she did, to determine the phase of the estrous cycle. The obtaining of vaginal smears was minimized to reduce possible interference (e.g., conditioning) brought about by repeated smearing. Vaginal lavage was performed with an eyedropper containing a small amount of physiological saline. Smears containing nucleated cells and perhaps a small proportion of leucocytes were considered to be proestrus (P) smears; smears containing nucleated cells and a small proportion of cornified cells were considered to be late proestrus (LP) smears; those containing predominantly cornified cells with a small proportion of nucleated cells were noted as estrus smears (E); those containing cornified cells, leucocytes, and perhaps some goblet cells were considered to be metestrus (M); smears containing almost all leucocytes were considered diestrus smears (D). Late proestrus, although not usually considered to be a distinct stage of the estrous cycle, is an important guide point in time breeding, and is therefore always noted when observed in rats in our laboratory.

Estrous cycle time-sample. The estrous smear schedule used (one smear obtained on the day of placentophagia), while minimizing the possible interference produced by repeated smearing, did not allow for the determination of the stage of the estrous cycle of females that did not eat on each day of testing. Therefore, to determine whether the distribution of placentophagia across the stages of the estrous cycle was random, and whether differences observed in our tests were a function of the duration of each stage of the cycle (e.g., whether the proportion of females eating placenta for the first time is less in one stage than in another because the female is less likely to be tested in that stage), the probability of a female being in each stage of the cycle on any test day was approximated with the use of a time-sample technique. Vaginal smears were obtained on 8 successive days from 119 additional CR-born virgins and from 23 additional RL-born virgins, between 1:00 and 3:00 p.m. Not all females were tested during the same 8 day period. The proportion of estrus, metestrus, diestrus, proestrus, and late proestrus smears was computed, yielding a close approximation of the probability of being in a particular stage of the estrous cycle on each test day, during the placentophagia test period. The probabilities were then used to compute expected frequencies of eaters with which observed frequencies were compared.

\section{RESULTS AND DISCUSSION}

The probabilities associated with being in a particular stage of the estrous cycle during the hours of testing on any test day (estrous cycle time-sample) differed for the CR-born and RL-born females. The probabilities (proportion of smears of each stage of the cycle) are summarized in Table 1.

Because of the controversy over whether metestrus is a stage distinctly different from the first of two diestrus days, and the difficulty in reliably distinguishing between diestrus 
TABLE 1

PROPORTION OF VAGINAL SMEARS OF EACH STAGE OF THE ESTROUS CYCLE OF CR-BORN AND RL-BORN VIRGINS*

\begin{tabular}{lccccc}
\hline Group & N & P & $\begin{array}{c}\text { Proportion of Smears in } \\
\text { Each Stage of Cycle } \\
\text { LP }\end{array}$ & E & M-D \\
\hline $\begin{array}{c}\text { CR-born } \\
\text { Nulliparous }\end{array}$ & 119 & 0.116 & 0.057 & 0.215 & 0.612 \\
$\begin{array}{c}\text { RL-born } \\
\text { Nulliparous }\end{array}$ & 23 & 0.219 & 0.075 & 0.150 & 0.556 \\
\hline
\end{tabular}

*Obtained from each female over 8 consecutive days.

and metestrus smears (a difficulty that does not arise in distinguishing between any other two stages), diestrus and metestrus data were pooled.

The RL-born females manifested a higher proportion of proestrus smears, a lower proportion of estrus smears, and a lower proportion of metestrus-diestrus smears at the time of day of testing, than did the CR-born females $\left(x^{2}(3)=\right.$ $15.51 ; p<0.01)$. We can only speculate on the reason for this difference at this point. A difference in diurnal rhythmicity due to different day-night cycles in our laboratory and in the Charles River breeding colony is a possible explanation, although the CR-born females had spent a minimum of four weeks in our laboratory prior to testing.

The incidence of eating placenta for the first time in CR-born and RL-born virgin females, and the stage of the estrous cycle in which eating occurred, are depicted in Table 2.

The most striking difference between the CR-born and RL-born virgins is the difference in the number of placentophages in each group.

The proportion of placentophages in the CR-born group $(0.465 \pm 0.044)$ was significantly higher than that of the RL-born Group $(0.041 \pm 0.023)$ when using the standard error of the difference between two proportions [1] ( $\tilde{\sigma} \mathrm{p}_{1}$ - $\left.\hat{\mathrm{p}}_{2}=0.068 ; z=6.283 ; p<0.0001\right)$. Whether this difference can be attributed to genetic factors (i.e., inadvertent selection for non-eating when breeding the mothers of the females of the RL-born group) cannot be determined at this time without additional information on the pedigree of the CR-born females and without a controlled selection study. We have determined, however, that $37.8 \%$ of the virgins of the RL-born group were derived from CR-born mothers that had eaten placenta in a pretest, and $62.2 \%$ were derived from CR-born mothers that did not eat.

Since the time-sample results differed for each group, we decided to compare the CR-born experimental females against the time-sample conducted on CR-born females. The low incidence of placentophagia in the RL-born group made subsequent analysis of estrous cycle influences in this group impossible.

The observed frequencies of placentophagia in different stages of the estrous cycle in the CR-born females were compared with expected frequencies derived by multiplying the time-sample probabilities by the total number of placentophages $(n=59)$ in the CR-born group. This computation provided the likelihood of eating in a particular stage of the cycle as a function of the duration of each stage, if placentophagia were randomly distributed across the whole cycle. The expected and observed frequencies are summarized in Table 3.

The distribution of the occurrence of eating placenta for the first time across the stages of the estrous cycle $(O)$ was significantly different from the expected frequency distribution $(E)$ based on the estrous cycle time-sample $\left(\chi^{2}(3)\right.$ $=14.03 ; p<0.01)$. The difference between the expected and observed distributions lies in the lower-than-expected number of females eating placenta during proestrus, and the greater-than-expected number of females eating placenta during estrus.

Placentophagia was not evenly distributed over the days of testing. Of the 59 females exhibiting placentophagia, 48 ate placenta on the first day of testing, 6 ate on the second day, and 5 ate on the third day. Of the 22 females who ate in estrus, all 22 were in estrus on the first day of testing. The proportion of females in estrus on the first day of testing (whether they ate placenta or not) was about what was expected from the estrous cycle time-sample $(22-23 \%)$. It appears that there was an interaction between stage of estrous cycle and test day, in that females in estrus on Day 1 were more likely to eat than other females on Day 1, or than estrus females on Day 2 or Day 3. Additional information regarding this apparent interaction was obtained in Experiment 2.

\section{EXPERIMENT 2}

To establish the reliability of the distribution of placentophagia across the stages of the estrous cycle observed in Experiment 1, we decided to test another large group of CR-born virgins. This time, however, we decided to obtain vaginal smears before rather than after testing, and on each test day rather than only on the day that the animal ate placenta. We also withheld the presentation of placenta to females in proestrus; because of the zero incidence of placentophagia during proestrus in Experiment 1 , our prediction was that omitting the proestrus presentations would not affect the incidence of placentophagia or the distribution of placentophagia over the other stages of the cycle.

Since the test females of Experiments 1 and 2 were housed in pairs, a cage-mate analysis was conducted on the females of Experiment 2, to determine whether cage mates behaved more similarly toward placenta than did non-cage mates.

\section{METHOD}

\section{Animals}

One hundred nineteen CR-born Long-Evans virgins, previously unexposed to placenta, that had served to establish the estrous cycle time-sample in Experiment 1, served as test animals in Experiment 2 (CR-born B). The females were comparable in age, weight, and housing conditions to the CR-born virgins in Experiment 1 that served as the comparison group (denoted in this experiment as CR-born A).

\section{Procedure}

Procedures for placenta collection and placenta presentation were identical to those used in Experiment 1. Test procedures were the same as in Experiment 1. Vaginal smears were obtained immediately prior to placenta pre- 
TABLE 2

INCIDENCE OF PLACENTOPHAGIA IN EACH STAGE OF THE ESTROUS CYCLE IN CR-BORN AND RL-BORN VIRGINS

\begin{tabular}{|c|c|c|c|c|c|c|c|}
\hline \multirow[b]{2}{*}{ Group } & \multicolumn{4}{|c|}{$\begin{array}{l}\text { No. Eating for First Time } \\
\text { in Each Stage of the } \\
\text { Estrous Cycle }\end{array}$} & \multirow{2}{*}{$\begin{array}{l}\text { Total } \\
\text { Eating }\end{array}$} & \multirow[b]{2}{*}{$\begin{array}{l}\text { Total } \\
\text { Tested }\end{array}$} & \multirow[b]{2}{*}{$\begin{array}{l}\text { Prop. } \\
\pm \text { SEP }\end{array}$} \\
\hline & $\mathrm{P}$ & LP & $\mathrm{E}$ & M-D & & & \\
\hline \multicolumn{8}{|l|}{ CR-born } \\
\hline Nulliparous & 0 & 4 & 22 & 33 & 59 & 127 & $0.465 \pm 0.044$ \\
\hline \multicolumn{8}{|l|}{ RL-born } \\
\hline Nulliparous & 0 & 1 & 0 & 2 & 3 & 74 & $0.041 \pm 0.023$ \\
\hline
\end{tabular}

TABLE 3

COMPARISON OF OBSERVED FREQUENCY OF PLACENTOPHAGIA IN CR-BORN VIRGINS* IN EACH STAGE OF THE CYCLE, WITH EXPECTED FREQUENCY BASED ON ESTROUS CYCLE TIME-SAMPLE

\begin{tabular}{lccc}
\hline Stage & $\begin{array}{c}p \text { from } \\
\text { Time-Sample }\end{array}$ & $\mathrm{E}$ & $\mathrm{O}$ \\
\hline Proestrus & 0.116 & 6.82 & 0 \\
Late Proestrus & 0.057 & 3.35 & 4 \\
Estrus & 0.215 & 12.70 & 22 \\
Metestrus- & 0.612 & 36.13 & 33 \\
Diestrus & & \\
\hline
\end{tabular}

$* \mathrm{~N}=59$.

sentation in the CR-born B Group, whereas they had been obtained immediately after the 15 -min placenta presentation in the CR-born A Group. The taking of vaginal smears began 3 days prior to the first day of placentophagia testing for the CR-born B Group. During the 5-day test period, females of the CR-born B Group that were determined to be in proestrus on a test day were not presented with placenta, and that day was dropped from the sequence.

\section{RESULTS AND DISCUSSION}

A comparison of the CR-born A and CR-born B Groups, in terms of the incidence of placentophagia and the frequency distribution of placentophagia across the stages of the estrous cycle, is presented in Table 4.

The proportion of placentophages in the CR-born B Group was not different from that of the CR-born A Group of Experiment $1\left(\hat{\sigma}_{\hat{p} 1}-\hat{p}_{2}=0.064 ; z=0.302 ; p>0.70\right)$. Furthermore, the distribution of placentophagia across stages of the estrous cycle was not significantly different in the two groups $\left(\chi^{2}(3)=0.45 ; p>0.90\right)$. Eliminating proestrus tests had no effect on the incidence of placentophagia in the CR-born B Group; and elimination of proestrus tests and the change from posttest to pretest smears had no effect on the distribution of placentophagia across stages of the estrous cycle in the CR-born B Group.

For the cage-mate analysis, the observed frequencies for cages in which both members of the pair ate, one member of the pair ate, and neither member of the pair ate, were compared to expected frequencies computed from the number of cages (59), the overall probability of eating $(0.455$, see Table 4$)$, and the probability of not eating (l-p= 0.545 ). The results are summarized in Table 5 .

The difference between the expected and observed values for 0,1 , or 2 members of a cage pair eating placenta were not significantly different $\left(x^{2}(2)=0.241 ; p>0.80\right)$, indicating that paired housing did not introduce interfemale influences in the testing situation.

The influence of day of testing was also examined, as it was in Experiment 1. The number of CR-born B females tested in each stage of the estrous cycle on each test day, and the number of females eating placenta in each stage of the estrous cycle on each test day, are summarized in Table 6. Since no placentophagia occurred after the first 3 test days, only the data from the first 3 days are presented.

Clearly, if a virgin ate placenta, she was most likely to have done it on the first day of testing. Furthermore, females in estrus on Day 1 were more likely to eat than if estrus occurred on Day 2 or Day 3. The figures for the entire estrus stage $(17 / 83)$ can be accounted for by the estrus eaters on Day 1. It should be noted that estrus occurred with higher than expected frequency on Day 1 in this group. That was because we frequently started testing the females on the first day after proestrus. In a group of 119 cycling females not tested during proestrus, we would have expected the proportion of females in estrus on Day 1 to be 0.244 (by adjustment of the estrous cycle timesample frequencies). The actual proportion of females in estrus on Day 1 in this group proved to be $0.387(46 / 119)$. The interaction between stage of the estrous cycle and day of testing, hypothesized in Experiment 1, was not supported by the data in Experiment 2. The proportion of females tested in estrus on Day 1 that ate placenta on Day $1(0.34$, see Table 6$)$ was not larger than the proportion of females tested in metestrus-diestrus on Day 1 that ate placenta on Day 1 (0.33). The proportion of females tested in late proestrus on Day 1 that ate placenta on Day 1 (0.20), was not much smaller than the proportions for the other stages. The proportions for the total eaters/total tests in each stage also showed no differences (estrus $=0.20$; metestrus-diestrus $=0.19$; late proestrus $=0.18$ ). It is clear, therefore, that the probability of eating placenta is greater on the first day of testing, but is not greater if the female is in estrus, as suggested in the first experiment.

\section{EXPERIMENT 3}

Experiments 1 and 2 were designed to examine the 
TABLE 4

INCIDENCE OF PLACENTOPHAGIA IN EACH STAGE OF THE CYCLE IN CR-BORN VIRGINS TESTED IN ALL STAGES AND IN CR-BORN VIRGINS TESTED ONLY IN NONPROESTRUS STAGES

\begin{tabular}{lccccccc}
\hline & \multicolumn{3}{c}{$\begin{array}{c}\text { No. Eating for First Time } \\
\text { in Each Stage of the } \\
\text { Estrous Cycle }\end{array}$} & M-D & $\begin{array}{c}\text { Total } \\
\text { Eating }\end{array}$ & $\begin{array}{c}\text { Total } \\
\text { Tested }\end{array}$ & $\begin{array}{c}\text { Prop. } \\
\pm \text { SEP }\end{array}$ \\
Group & P & LP & E & M- & & & \\
CR-born A & 0 & 4 & 22 & 33 & 59 & 127 & $0.465 \pm 0.044$ \\
CR-born B & - & 3 & 17 & 33 & 53 & 119 & $0.445 \pm 0.046$ \\
\hline
\end{tabular}

TABLE 5

OBSERVED AND EXPECTED FREQUENCIES OF PAIRS OF VIRGINS HOUSED TOGETHER IN WHICH 0, 1, OR 2 MEMBERS OF PAIR ATE PLACENTA*

\begin{tabular}{lccc}
\hline Combination & $p$ & $\mathrm{E}$ & $\mathrm{O}$ \\
\hline Neither Ate & 0.297 & 17.51 & 17 \\
One Ate & 0.496 & 29.27 & 31 \\
Both Ate & 0.207 & 12.23 & 11 \\
\hline
\end{tabular}

$* N=59$ pairs.

influence of stages of the estrous cycle on the initiation of placentophagia, i.e., eating placenta for the first time, by naive virgins. In Experiment 1, we found that females would not initiate placentophagia in proestrus. The question remained, whether proestrus females would eat placenta after they had manifested placentophagia in another stage of the cycle. If not, the indication would be that proestrus was always associated with a suppression of placentophagia. Experiment 3 was designed to test whether females that ate placenta for the first time in a nonproestrus stage would subsequently eat placenta when tested in proestrus.

\section{METHOD}

\section{Animals}

Forty-two CR-born virgins, determined to be placentophages in a pretest, were used as subjects. None of the rats had initiated placentophagia during proestrus in the pretest.

\section{Procedure}

Procedures for placenta collection and presentation were identical to those of the previous 2 experiments.

Thirty days after pretesting, each female was retested for placentophagia in only one of three stages of the cycle: proestrus, diestrus, or estrus. The retest consisted of only one $15 \mathrm{~min}$ presentation of placenta, immediately after a vaginal smear was obtained. Of the 42 females, 13 were retested in proestrus, 14 in estrus, and 15 in diestrus.

\section{RESULTS AND DISCUSSION}

Of the 13 females retested during proestrus, 12 ate placenta ( 0.92$)$; of the 14 females retested during estrus, 12 ate placenta $(0.86)$; and of the 15 females retested during
TABLE 6

NUMBER OF CR-BORN EATERS IN EACH STAGE ON EACH TEST DAY PER NUMBER TESTED IN EACH STAGE ON EACH TEST DAY*†

\begin{tabular}{|c|c|c|c|c|}
\hline Test Day & \multicolumn{3}{|c|}{ Stage of Cycle } & $\begin{array}{c}\text { Total Eaters } \\
\text { Per Total } \\
\text { Animals Tested }\end{array}$ \\
\hline Day 1 & $16 / 46$ & $21 / 63$ & $2 / 10$ & $39 / 119$ \\
\hline Day 2 & $0 / 21$ & $5 / 54$ & $1 / 5$ & $6 / 80$ \\
\hline Day 3 & $1 / 16$ & $7 / 56$ & $0 / 2$ & $8 / 74$ \\
\hline $\begin{array}{l}\text { Total Eaters } \\
\text { Per Presenta- } \\
\text { tions }\end{array}$ & $17 / 83$ & $33 / 173$ & $3 / 17$ & \\
\hline
\end{tabular}

$* \mathrm{~N}=119$ animals.

†Proestrus tests not conducted.

diestrus, 15 ate placenta (1.00).

It is clear that being in proestrus decreases to 0 the probability of eating placenta for the first time for the naive virgin rat. However, having first eaten placenta in a non-proestrus stage (prior experience) makes eating placenta in a subsequent proestrus as probable as eating placenta in a non-proestrus stage.

\section{EXPERIMENT 4}

Kristal has demonstrated in previous studies $[4,7]$ that the incidence of placentophagia in parturitionally experienced nonpregnant rats and mice was significantly increased over that observed in nulliparous nonpregnant rats and mice. Furthermore, there were strain differences in the amount of increase observed in mice. Since the rats used in the previous study [4] were albinos, it seemed necessary at this point to test Long-Evans females that had had parturitional experience.

Both CR-born and RL-born females were tested. Experiment 1 had indicated that the responses of the two groups, as virgins, were significantly different. Experiment 4 examined whether RL-born females, after the acquisition of parturitional experience, still manifested an incidence of placentophagia significantly lower than that of a comparable group of CR-born females, or whether the location of birth and rearing (Charles River breeding colony), or possibly the shipping process, inflated the values only for the virgin group. The influence of proestrus on the likelihood of eating foster placenta for the first time, in parturitionally experienced animals, was also investigated. 
METHOD

\section{Animals}

Twenty-six CR-born and 19 RL-born rats were tested for placentophagia 3 weeks after they had weaned their first litters (Primiparous). Twenty-one CR-born females were tested for placentophagia 3 weeks after they had weaned their second litters (Multiparous).

The nulliparous CR-born and RL-born females from Experiment 1 served as comparison groups.

\section{Procedure}

Prior to impregnation, each female was housed individually in a wire-mesh cage. At about 75 days of age, each female was bred to a stud male in our laboratory and then placed in a $40 \times 20 \times 15-\mathrm{cm}$ plastic cage containing sawdust, where she remained throughout pregnancy and lactation. At weaning ( 28 days postpartum), the mother was returned to an individual wire-mesh cage. Placentophagia tests were conducted three weeks after removal of the weaned litters. In the multiparous group, the females were remated 2 weeks after the first litter was weaned, and the female was then placed in another plastic cage until the second litter reached weaning age. Vaginal smears were obtained daily from each female, prior to the presentation of placenta.

\section{RESULTS AND DISCUSSION}

The data for Experiment 4 are summarized in Table 7 .

In Experiment 1, the incidence of placentophagia in CR-born nulliparous rats was significantly greater than that of RL-born rats. The incidence of placentophagia in the RL-born Primiparous Group (0.579 \pm 0.149$)$ was significantly higher than that of the RL-born Nulliparous Group $\left(0.041 \pm 0.023 ; \hat{\sigma}_{\hat{\mathrm{p}} 1}{ }_{\mathrm{n}} \mathrm{\textrm {p }} 2=0.092 ; z=5.86\right.$; $p<0.0001)$. Furthermore, the incidence of placentophagia in the RL-born Primiparous Group was not significantly different from that of the CR-born Primiparous Group $\left(0.615 \pm 0.095 ; \hat{\sigma}_{\hat{p}_{1}}-\hat{\mathrm{p}}_{2}=0.148 ; z=0.25 ; p>0.4\right)$. Although the incidence of placentophagia in the CR-born Nulliparous Group $(0.465 \pm 0.044)$ was significantly lower than that of the CR-born Multiparous Group $(0.762 \pm$ $\left.0.093 ; \hat{\sigma}_{\hat{\mathrm{p}}} 1-\hat{\mathrm{p}}_{2}=0.115 ; z=2.591 ; p<0.005\right)$, the CR-born Primiparous Group was not significantly different from either the CR-born Nulliparous Group $\left(\hat{\sigma} \hat{\mathrm{p}}_{1}-\mathrm{p}_{2}=\right.$ $0.108 ; z=1.40 ; p>0.05)$ or the CR-born Multiparous

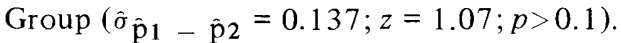

Proestrus was found not to influence placentophagia in any of the parturitionally experienced placentophages. The likelihood of eating placenta for the first time in proestrus, for both the CR-born and RL-born rats, was equal to that in the other stages of the cycle.

The CR-born and RL-born females differ in their response to placenta only as virgins. Parturitional experience increases the likelihood of placentophagia in the nonpregnant condition in both groups, but whether the incidence of placentophagia in RL-born virgins is exceptionally low or the incidence of placentophagia in CR-born virgins is exceptionally high, is still not completely clear; in view of previous research on rats [4] and on mice $[5,7]$, it would seem that the latter is the more likely.
TABLE 7

PLACENTOPHAGIA IN NONPREGNANT CR-BORN AND RL-BORN RATS OF DIFFERENT LEVELS OF PARITY

\begin{tabular}{lrc}
\hline Group & $\mathrm{N}$ & Prop. \pm SEP \\
\hline RL-Born & & \\
$\quad$ Nulliparous (from Exp. 1) & 74 & $0.041 \pm 0.023$ \\
$\quad$ Primiparous & 19 & $0.579 \pm 0.149$ \\
CR-born & & \\
$\quad$ Nulliparous (from Exp. 1) & 127 & $0.465 \pm 0.044$ \\
Primiparous & 26 & $0.615 \pm 0.095$ \\
$\quad$ Multiparous & 21 & $0.762 \pm 0.093$ \\
\hline
\end{tabular}

\section{GENERAL DISCUSSION}

In summary, we observed that (a) virgins purchased from a commercial breeder (CR-born) were more likely to eat foster placenta than were virgins born and raised in our laboratory (RL-born); (b) CR-born virgins did not eat foster placenta for the first time if they were in proestrus; (c) nonpregnant rats that would eat placenta were most likely to have eaten it, for the first time, on the first presentation; (d) if a CR-born female ate foster placenta for the first time in a nonproestrus stage (or at partutition), she would subsequently eat placenta in proestrus; (e) both nonpregnant RL-born and nonpregnant CR-born females showed an increased likelihood of placentophagia if they had had previous partutitional experience; (f) despite differences between virgin RL-born and CR-born females, the behavior of nonpregnant primiparous CR-born and RL-born females toward foster placenta was the same.

It is difficult, at this point, to account for the striking difference in response of $\mathrm{RL}$-born and $\mathrm{CR}$-born virgins toward foster placenta. As mentioned earlier, we do not believe that the difference can be accounted for by inadvertent selection; nevertheless, genetic selection as an explanation of the differences can be ruled out only by conducting the proper selection experiment. Another possibility is that the Charles River breeding colony allowed their breeder females to be mated during the postpartum estrus, thereby exposing weanlings to placentophagia on the part of the mother as she delivered a subsequent litter. This possibility can apparently be ruled out. $\mathrm{Mr}$. T. D. McCormack of the Charles River Breeding Laboratories stated (personal communication, 27 March 1975) that the breeding procedure at Charles River precludes impregnation during the postpartum estrus. A third possibility is that CR-born females differ from RL-born females in that they have undergone the stress of being crated and shipped from one colony to another, which may have produced prolonged, or possibly permanent, physiological changes.

The distribution over the stages of the estrous cycle of eating placenta for the first time indicates clearly that there is something unique about the proestrus stage in CR-born virgins. Unfortunately, the incidence of placentophagia in RL-born virgins is so low that it was not possible to analyze the response of $\mathrm{RL}$-born virgins to placenta as a function of stage of the estrous cycle. We do not know, therefore, whether the proestrus inhibition of eating foster placenta for the first time is unique to CR-born females. The observed effect of proestrus on placentophagia may be attributable directly to ovarian hormone changes (e.g., 
estrogen concentration peaks during proestrus $[10,14])$, but it is not simply the result of changes in feeding and drinking behavior that are correlated with stages of the cycle. Tarttelin and Gorski [12] have demonstrated that during proestrus the food and water intakes are intermediate between the high levels observed during diestrus, and the low levels observed during estrus. The fact that virgins do not eat foster placenta for the first time when they are in proestrus remains puzzling, and is further complicated by the finding that virgins do eat placenta in proestrus if they previously ate placenta in a nonproestrus stage of the cycle.
Finally, nonpregnant Long-Evans rats are more likely to ingest foster placenta if they have had parturitional experience. These data are consonant with data obtained from albino rats [4] and from two inbred strains of mice [7].

The data indicate that since placentophagia is affected by stage of the estrous cycle, birthplace, parturitional experience, and (from previous studies $[5,7]$ ) genotype, placenta occupies a unique place in the spectrum of ingestible substances for the rodent.

\section{REFERENCES}

1. Dixon, W. J. and F. J. Massey. Introduction to Statistical Analysis. New York: McGraw-Hill, 1969.

2. Hafez, E. S. E., M. W. Schein and R. Ewbank. The behaviour of cattle. In: The Behaviour of Domestic Animals, edited by E. S. E. Hafez. Baltimore: Williams and Wilkins, 1969.

3. Hediger, H. Studies of the Psychology and Behaviour of Captive Animals in Zoos and Circuses. London: Butterworth and Company, Ltd., 1955.

4. Kristal, M. B. Effects of lateral hypothalamic lesions on placentophagia in virgin, primiparous, and multiparous rats. $J$. comp. physiol. Psychol. 84: 53-62, 1973.

5. Kristal, M. B. and B. E. Eleftheriou. Placentophagia in nonpregnant nulliparous mice: A genetic investigation. Behav. Biol. 13: 113-119, 1975.

6. Kristal, M. B. and R. S. Wampler. Food and water intake prior to parturition in the rat. Physiol. Psychol. 1: 297-300, 1973.

7. Kristal, M. B. and C. L. Williams. The effects of strain, reproductive condition, and strain of placenta donor on placentophagia in nonpregnant mice. Physiol. Psychol. 1: $354-356,1973$.

8. Lehrman, D. S. Hormonal regulation of parental behavior in birds and infrahuman mammals. In: Sex and Internal Secretions. Vol. II, edited by W. C. Young. Baltimore: Williams and Wilkins, 1961.
9. Richter, C. P. and B. Barelare. Nutritional requirements of pregnant and lactating rats studied by the self-selection method. Endocrinology 23: 15-24, 1938.

10. Schwartz, N. B. A model for the regulation of ovulation in the rat. Recent Progress in Hormone Research. Vol. 25. New York: Academic Press, 1969.

11. Slijper, E. J. Die Geburt der Säugertiere. In: Handbuch der Zoologie, Vol. 8, edited by J. G. Helmcke, H. v. Lengerken and D. Starck. Berlin: Walter de Gruyter, 1960.

12. Tarttelin, M. F. and R. A. Gorski. Variations in food and water intake in the normal and acyclic female rat. Physiol. Behav. 7: $847-852,1971$.

13. Tinklepaugh, O. L. and C. G. Hartmann. Behavioral aspects of parturition in the monkey (Macacus rhesus). J. comp. Psychol. 11: $63-98,1930$.

14. Yoshinaga, K., R. A. Hawkins and J. F. Stocker. Estrogen secretion by the rat ovary in vivo during the estrous cycle and pregnancy. Endocrinology 85: 103-112, 1969.

15. Zarrow, M. X., V. H. Denenberg and B. D. Sachs. Hormones and maternal behavior in mammals. In: Hormones and Behavior, edited by S. Levine. New York: Academic Press, 1972. 